Check for updates

London

Cite this as: $B M J$ 2021;372:n130 http://dx.doi.org/10.1136/bmj.n130 Published: 14 January 2021

\section{Covid-19: Convalescent plasma may cut deaths in patients not on ventilation, study indicates}

\author{
Jacqui Wise
}

Any benefit of convalescent plasma seems to be most apparent in patients who receive transfusions containing high levels of antibodies early in the course of the disease, an observational study concludes. ${ }^{1}$

However, experts say that results of randomised trials are needed to know whether there is a true beneficial effect from convalescent plasma. The RECOVERY trial, the world's largest trial of treatments in covid-19, is expected to announce results in the next two weeks. It has more than 10 ooo patients in its comparison of convalescent plasma with usual NHS care alone.

In August 2020 the US Food and Drug Administration approved convalescent plasma for emergency use in hospital patients with covid-19 despite warnings over lack of evidence from randomised controlled trials. ${ }^{23}$ A randomised controlled trial from India published in The BMJ in November found that convalescent plasma was not associated with a reduction in progression to severe covid-19 or in mortality from all causes. ${ }^{4}$

On 11 January the REMAP-CAP trial announced that it had halted recruitment to its convalescent plasma arm on the recommendation of the data safety monitoring board. An interim analysis that was based on data from 912 patients found that the probability that convalescent plasma was beneficial was $2.2 \%$. The trial is looking at several potential treatments for severely ill covid-19 patients who are in intensive care.

The latest study, published in the New England Journal of Medicine, ${ }^{1}$ included 3082 hospital patients with covid-19 on a US national registry who were given convalescent plasma as part of the Mayo Clinic's expanded access programme for patients with the disease. The patients were classified into three groups with high, medium, and low antibody concentrations.

The retrospective study found a trend towards improved mortality the higher the level of antibody in the convalescent plasma. Death within 30 days of plasma transfusion occurred in 115 of 515 patients (22.3\%) in the high titre group, 549 of 2006 (27.4\%) in the medium titre group, and 166 of 561 patients $(29.6 \%)$ in the low titre group.

However, a lower risk of death within 30 days in the high titre group than in the low titre group was seen only in patients who had not received mechanical ventilation before transfusion (relative risk 0.66 (95\% confidence interval 0.48 to 0.91 )). The researchers found no relation between antibody concentration and risk of death among patients with covid-19 who were receiving mechanical ventilation before transfusion.

The patients who received plasma within three days after the diagnosis of covid-19 had a lower risk of death than those who received a transfusion later in the disease course, the study found.

The study had several limitations. It had an open label design and lacked a randomised placebo group. The authors also acknowledged that they "determined a priori that the low titre group may have been at higher risk for death than the high titre group."

Commenting on the study, Kamran Abbasi, executive editor of The BMJ, said, "I'm surprised that this study was influential enough to help persuade the US Food and Drug Administration to issue an emergency use authorisation for convalescent plasma.

"It's a good research question, but the retrospective study design means that we can't conclude whether convalescent plasma is helpful or not. The evidence so far, even from randomised trials, doesn't suggest this treatment is beneficial. That may change with other trials due to report, but I wouldn't recommend convalescent plasma as a treatment for covid-19 on the basis of this study."

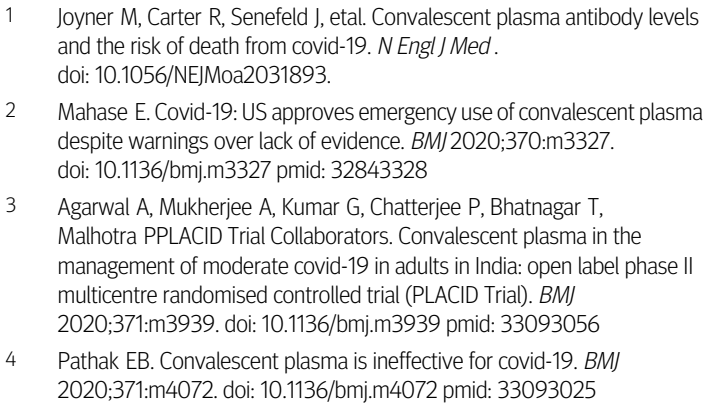

2 Mahase E. Covid-19: US approves emergency use of convalescent plasma despite warnings over lack of evidence. BM/2020;370:m3327. doi: 10.1136/bmj.m3327 pmid: 32843328

3 Agarwal A, Mukherjee A, Kumar G, Chatterjee P, Bhatnagar T, Malhotra PPLACID Trial Collaborators. Convalescent plasma in the management of moderate covid-19 in adults in India: open label phase ॥ multicentre randomised controlled trial (PLACID Trial). BMJ 2020;371:m3939. doi: 10.1136/bmj.m3939 pmid: 33093056

4 Pathak EB. Convalescent plasma is ineffective for covid-19. BMJ 2020;371:m4072. doi: 10.1136/bmj.m4072 pmid: 33093025

This article is made freely available for use in accordance with BMJ's website terms and conditions for the duration of the covid-19 pandemic or until otherwise determined by BMJ. You may use, download and print the article for any lawful, non-commercial purpose (including text and data mining) provided that all copyright notices and trade marks are retained. 